\title{
The Study on Dynamic Supply Chain Coordination under the Premise of Risk-neutral
}

\author{
Gao Benhe \\ Graduate School at Shenzhen \\ Tsinghua University \\ Shenzhen, China \\ gaobh@sz.tsinghua.edu.cn \\ Liu Rongzhi \\ Graduate School at Shenzhen \\ Tsinghua University \\ Shenzhen, China \\ 1rz13@mails.tsinghua.edu.cn
}

\author{
Zhao Yanbei \\ Graduate School at Shenzhen \\ Tsinghua University \\ Shenzhen, China \\ shelley1992@126.com \\ Liu Pingyuan \\ Graduate School at Shenzhen \\ Tsinghua University \\ Shenzhen, China \\ liupy@csg.cn
}

\begin{abstract}
In risk-neutral case, we obtain the coordination strategy of a two-stage supply chain in buy-back contract under the disruption of any two factors out of supplier's production cost, retailer's marginal cost and retail price. We analyze the relationship between the optimal order quantity after disruption and the previous optimized quantity, and list the expression of contract parameters adapted to emergency. The variation trends of different variables in the buy-back contract are showed through a case study at the end of the paper.
\end{abstract}

Keywords-emergency supply chain; buy-back contract; twofactor disruptions; coordination

\section{INTRODUCTION}

The internal and external environment of a supply chain is not always stable. A variety of factors in real cases affect the operation of the optimal plan, whose effects on the supply chain are quite different. The uncertainty and adverse effect of unexpected events draw more and more attention to the emergency supply chain management from both academic and enterprise fields. The purpose of the study of emergency supply chain management is to control the whole process of emergencies so as to reduce the adverse effects on and strengthen the anti-risk ability of enterprises as far as possible. The most common approach is to make use of contracts to coordinate the supply chain. According to the features of emergency, we need to adjust contract parameters in time.

Yu et al put forward a new quantity discount contract when emergencies caused the change of demand sensitive coefficient and the extra cost was nonlinear[1]; $\mathrm{Xu}$ created a quantity discount contract when emergencies caused the change of market size and the extra cost was linear[2]; $\mathrm{Xu}$ et al then researched on linear and nonlinear price demand function, and obtained the coordination strategy in centralized and decentralized decision making when production cost changed[3]; Zhuang and Zhao showed the supply chain coordination in centralized and decentralized wholesale price contract when emergencies caused the change of retailer cost
[4]; Wang and $\mathrm{Hu}$ analyzed a three-stage supply chain coordination strategy in centralized and decentralized quantity discount contract when emergencies caused the change of market demand and the extra cost was nonlinear[5]; Qi created a new quantity discount contract when emergencies caused the change of market demand and the demand function was linear[6]; $\mathrm{Xu}$ et al assumed the demand function was nonlinear and discussed the quantity discount contract when emergencies caused the change of market demand and the extra cost was linear[7]; Yu et al presented the improved buy-back contract by adjusting the wholesale price contract to respond to emergencies [8]; Niu studied the revenue sharing contract coordination strategy by adjusting wholesale price and revenue sharing coefficient when market demand disrupted[9]; Qin and Fu created a new buy-back contract to coordinate the supply chain when emergencies caused the change of market demand [10].

Although the above literatures on supply chain contract consider some constraints, most of them are modeled and analyzed in the case of single disruption. However, in real cases, several factors including cost and price often disrupt simultaneously, which requires supply chain members to adjust the previous contract in order to adapt to different emergencies. According to the basic conditions of supply chain coordination, this paper explores the coordination strategy in buy-back contract when any two factors disturb.

\section{SUPPLY CHAIN DECISION MODEL UNDER RISK-NEUTRAL CONDITION}

In cooperation, supply chain members often have different risk tolerance abilities due to various operation philosophies, enterprise scales and business goals. Risk-seeking me mbers are usually willing to take bigger risks in order to get more benefits, while loss-averse members are very sensitive to risks. This paper assumes that supply chain members are risk-neutral and that there won't be risk-seeking or loss-aversion coefficients in the definition of parameters. 


\section{A. Parameter definition}

We consider a market supply chain consisting of an upper-stream supplier and a downstream retailer under the assumption that the supplier and the retailer share common market information and that the retailer deal with residual products. Basic parameters of the model are shown in Tab.1.

TABLE I. MODEL PARAMETERS

\begin{tabular}{cl}
\hline Parameter & \\
\hline$q$ & Order quant ity of the retailer \\
$f(x)$ & Stochastic demand of the product \\
$F(x)$ & Demand probability density function, expect ation $\mu$ \\
$c_{s}$ & Demand distribution function \\
$c_{r}$ & Unit marginal cost of the retailer \\
$c$ & Unit cost, $c=c_{s}+c_{r}$ \\
$g_{s}$ & Unit penalty cost of the supplier's goodwill due to the \\
$g_{r}$ & Unit penalty cost of the retailer's goodwill due to the \\
$g$ & retailer's out of stock \\
$p$ & Unit penalty cost of the supply chain's goodwill \\
$v$ & Unit retail price of the product \\
$w_{b}$ & Unit residual value of the product \\
$b$ & Unit buy-back price of the product
\end{tabular}

In a totally competitive market, retail price is decided by the market, the three most common disruption variables are: retail price $\mathrm{p}$, unit production $\cos t c_{s}$, unit marginal $\cos \mathrm{t} c_{r}$.

At the time of production plan adjustment, the supplier needs to pay extra cost. When the new order quantity $q$ is greater than the previous optimized quantity $q^{*}$, the supplier has to set up more machines, recruit more workers and purchase more raw materials, which require extra unit production $\cos t \lambda_{1}$ for the additional products $q-q^{*}$; on the other hand, when the new order quantity $q$ is less than the previous optimized quantity $q^{*}$, the supplier has to reduce production, which will leave current workers and machines unused, causing extra unit $\cos t \lambda_{2}$.

\section{B. Static buy-back contract coordination}

The form of buy-back contract is $\left(w_{b}, b\right), w_{b}$ is the wholesale price offered by the supplier, $b$ is the buy-back price. We can get:

Expected sales when the order quantity is $q$ :

$$
S(q)=\int_{0}^{q} x f(x) d x+\int_{q}^{\infty} q f(x) d x=q-\int_{0}^{q} F(x) d x
$$

Expected excess quantity when the order quantity is $q$ :

$$
I(q)=E\left[(q-x)^{+}\right]=q-S(q)
$$

Expected demand that hasn't been met when the order quantity is $q$ :

$$
L(q)=E\left[(x-q)^{+}\right]=\mu-S(q)
$$

Expected profit of the supply chain:

$$
\pi=(p-v+g) S(q)-(c-v) q-\mu g
$$

Maximizing equation (4), we get the optimal order quantity of a static supply chain contract:

$$
q^{*}=F^{-1}\left(\frac{p-c+g}{p-v+g}\right)
$$

Contract parameters are:

$$
\left\{\begin{array}{c}
w_{b}=p-c_{r}+g_{r}-\lambda(p-c+g) \\
b=p-v+g_{r}-\lambda(p-v+g)
\end{array}, \quad \lambda \geq 0\right.
$$

Among them, $\lambda$ is the revenue sharing coefficient of the retailer.

When the supply chain is in operation, uncertain effect of emergencies can cause the change of cost and price, which may change the retailer's optimal order quantity and may cause the incoordination of the original contract. Therefore, we need to research on dynamic buy-back contract. The supply chain's dynamicity is reflected through factor disruptions.

\section{BUY-BACK CONT RACT COORDINATION UNDER TWO-FACTOR DISRUPTIONS}

\section{A. Retail price disruption and production cost disruption}

We assume that emergencies cause the change of retail price and production cost, and that the deviations are $\Delta p$ and $\Delta c_{s}$ respectively.

In a supply chain coordinated by buy-back contract, the transfer payment offered to the supplier from the retailer is:

$$
T=w_{b} q-b I(q)=b S(q)+\left(w_{b}-b\right) q
$$

Expected profit of the retailer is:

$$
\begin{aligned}
& \pi_{r}=(p+\Delta p) S(q)+v I(q)-g_{r} L(q)-c_{r} q-T \\
& =\left(p+\Delta p-v+g_{r}-b\right) S(q)-\left(w_{b}-b+c_{r}-v\right) q-g_{r} \mu
\end{aligned}
$$

Expected profit of the supplier is:

$$
\begin{aligned}
& \pi_{s}=T-\left(c_{s}+\Delta c_{s}\right) q-g_{s} L(q)-\lambda_{1}\left(q-q^{*}\right)^{+}-\lambda_{2}\left(q^{*}-q\right)^{+} \\
& =\left(w_{b}-b-c_{s}-\Delta c_{s}\right) q+\left(b+g_{s}\right) S(q) \\
& -g_{s} \mu-\lambda_{1}\left(q-q^{*}\right)^{+}-\lambda_{2}\left(q^{*}-q\right)^{+}
\end{aligned}
$$

Expected profit of the supply chain is:

$$
\begin{aligned}
& \pi=\pi_{s}+\pi_{r}=(p+\Delta p-v+g) S(q)-\left(c+\Delta c_{s}-v\right) q \\
& -\mu g-\lambda_{1}\left(q-q^{*}\right)^{+}-\lambda_{2}\left(q^{*}-q\right)^{+}
\end{aligned}
$$

Relation between the retailers's expected profit and the supply chain's after disruption:

$$
\begin{aligned}
& \pi_{r}=\lambda \pi+(1-\lambda) \Delta p S(q)+\lambda \Delta c_{s} q+ \\
& \lambda\left[\lambda_{1}\left(q-q^{*}\right)^{+}-\lambda_{2}\left(q^{*}-q\right)^{+}\right]+\lambda \mu g-\mu g_{r}
\end{aligned}
$$


The retailer's profit is no longer an affine function of the supply chain's, which leaves the supply chain uncoordinated. Therefore, we need to adjust the contract parameters in order to re-coordinate the supply chain. Supply chain coordination often follows two basic theorems, we only give the conclusions due to complicated proof process:

Theorem1. Suppose retail price and production cost disrupt at the same time, and the optimal order quantity of the supply chain after disruption is $\bar{q}$.

If $\Delta p \geq \frac{p-v+g}{c-v} \Delta c_{s}$, then $\bar{q} \geq q^{*}$;

If $\Delta p \leq \frac{p-v+g}{c-v} \Delta c_{s}$, then $\bar{q} \leq q^{*}$.

Theorem2. Suppose retail price and production cost disrupt at the same time, then the optimal order quantity meet the following equation:

$$
\begin{aligned}
& \bar{q}=\left\{\begin{array}{lc}
q_{1}^{*} & \Delta p \geq \frac{p-v+g}{c-v}\left(\Delta c_{s}+\lambda_{1}\right) \\
q^{*} & \frac{p-v+g}{c-v}\left(\Delta c_{s}-\lambda_{2}\right) \leq \Delta p \leq \frac{p-v+g}{c-v}\left(\Delta c_{s}+\lambda_{1}\right) \\
q_{2}^{*} & \Delta p \leq \frac{p-v+g}{c-v}\left(\Delta c_{s}-\lambda_{2}\right)
\end{array}\right. \\
& q_{1}^{*}=F^{-1}\left(\frac{p+\Delta p+g-c-\Delta c_{s}-\lambda_{1}}{p+\Delta p-v+g}\right) \\
& q^{*}=F^{-1}\left(\frac{p-c+g}{p-v+g}\right) \\
& q_{2}^{*}=F^{-1}\left(\frac{p+\Delta p+g-c-\Delta c_{s}+\lambda_{2}}{p+\Delta p-v+g}\right)
\end{aligned}
$$

On the basis of the above two theorems, the previous buy-back contract cannot coordinate the supply chain after disruptions. We need to reset the parameters $\left(w_{b 1}, b_{1}\right)$ so that the retailer's profit is an affine function of the supply chain's, thus $\pi_{r}\left(q, w_{b 1}, b_{1}\right)=\lambda+\lambda \mu g-\mu g_{r}$, that is:

$$
\begin{aligned}
& \left(p+\Delta p-v+g_{r}-b_{1}\right) S(q)-\left(w_{b 1}-b_{1}+c_{r}-v\right) q-\mu g_{r} \\
& =\left(p-v+g_{r}-b+\lambda \Delta p\right) S(q)-\left\{\left(w_{b}-b+c_{r}-v+\lambda \Delta c_{s}\right) q\right. \\
& \left.-\lambda\left[\lambda_{1}\left(q-q^{*}\right)^{+}+\lambda_{2}\left(q^{*}-q\right)^{+}\right]\right\}-\mu g_{r}
\end{aligned}
$$

According to the expression of the retailer's expected profit, we establish the following equations:

$$
\left\{\begin{array}{l}
p+\Delta p-v+g_{r}-b_{1}=p-v+g_{r}-b+\lambda \Delta p \\
w_{b 1}-b_{1}+c_{r}-v=\left(w_{b}-b+c_{r}+\lambda \Delta c_{s}-v\right)+\frac{\lambda}{q}\left[\lambda_{1}\left(q-q^{*}\right)^{+}+\lambda_{2}\left(q^{*}-q\right)^{+}\right]
\end{array}\right.
$$

Corresponding wholesale price and buy-back price are:

$$
\left\{\begin{array}{l}
w_{b 1}=w_{b}+(1-\lambda) \Delta p+\lambda \Delta c_{s}+\frac{\lambda}{q}\left[\lambda_{1}\left(q-q^{*}\right)^{+}+\lambda_{2}\left(q^{*}-q\right)^{+}\right] \\
b_{1}=b+(1-\lambda) \Delta p
\end{array}\right.
$$

Applying (14) to the profit function of (8) and (10), we can find that the retailer's profit is still an affine function of the supply chain's. The supply chain is coordinated.

\section{B. Retail price disruption and marginal cost disruption}

We assume that emergencies cause the change of retail price and marg inal cost, and that the deviations are $\Delta p$ and $\Delta c_{r}$ respectively.

In the same way, we can get the optimal order quantity:

$$
\begin{gathered}
\bar{q}=\left\{\begin{array}{cc}
q_{1}^{*} & \Delta p \geq \frac{p-v+g}{c-v}\left(\Delta c_{r}+\lambda_{1}\right) \\
q^{*} & \frac{p-v+g}{c-v}\left(\Delta c_{r}-\lambda_{2}\right) \leq \Delta p \leq \frac{p-v+g}{c-v}\left(\Delta c_{r}+\lambda_{1}\right) \\
q_{2}^{*} & \Delta p \leq \frac{p-v+g}{c-v}\left(\Delta c_{r}-\lambda_{2}\right)
\end{array}\right. \\
q_{1}^{*}=F^{-1}\left(\frac{p+\Delta p+g-c-\Delta c_{r}-\lambda_{1}}{p+\Delta p-v+g}\right) \\
q^{*}=F^{-1}\left(\frac{p-c+g}{p-v+g}\right) \\
q_{2}^{*}=F^{-1}\left(\frac{p+\Delta p+g-c-\Delta c_{r}+\lambda_{2}}{p+\Delta p-v+g}\right)
\end{gathered}
$$

Expected profit of the retailer is:

$$
\begin{aligned}
& \pi_{r}=(p+\Delta p) S(q)+v I(q)-g_{r} L(q)-\left(\Delta c_{r}+c_{r}\right) q-T \\
& =\left(p+\Delta p-v+g_{r}-b\right) S(q)-\left(w_{b}+c_{r}+\Delta c_{r}-v-b\right) q-g_{r} \mu
\end{aligned}
$$

Expected profit of the supply chain is:

$$
\begin{aligned}
& \pi=(p+\square p-v+g) S(q)-\left(c+\Delta c_{r}-v\right) q \\
& -\mu g-\lambda_{1}\left(q-q^{*}\right)^{+}-\lambda_{2}\left(q^{*}-q\right)^{+}
\end{aligned}
$$

The previous buy-back contract cannot coordinate the supply chain after dis ruptions. We need to reset the parameters $\left(w_{b 2}, b_{2}\right)$ so that retailer's profit is an affine function of the supply chain's, thus $\pi_{r}\left(q, w_{b 2}, b_{2}\right)=\lambda+\lambda \mu g-\mu g_{r}$. According to the expression of the retailer's expected profit, we get the corresponding wholesale price and buy-back price:

$\left\{\begin{array}{l}w_{b 2}=w_{b}+(1-\lambda)\left(\Delta p-\Delta c_{r}\right)+\frac{\lambda}{q}\left[\lambda_{1}\left(q-q^{*}\right)^{+}-\lambda_{2}\left(q^{*}-q\right)^{+}\right] \\ b_{2}=b+(1-\lambda) \Delta p\end{array}\right.$

Applying (18) to the profit function of (16) and (17), we can find that the retailer's profit is still an affine function of the supply chain's. The supply chain is coordinated.

\section{Production cost disruption and marginal cost disruption}

We assume that emergencies cause the change of production cost and marg inal cost, and that the deviations are $\Delta c_{s}$ and $\Delta c_{r}$ respectively (total cost deviation $\Delta c=\Delta c_{s}+\Delta c_{r}$ ).

In the same way, we can get the optimal order quantity:

$$
\bar{q}=\left\{\begin{array}{lc}
F^{-1}\left(\frac{p+g-c-\Delta c+\lambda_{2}}{p-v+g}\right) & \Delta c \geq \lambda_{2} \\
F^{-1}\left(\frac{p-c+g}{p-v+g}\right) & -\lambda_{1} \leq \Delta c \leq \lambda_{2} \\
F^{-1}\left(\frac{p+g-c-\Delta c-\lambda_{1}}{p-v+g}\right) & \Delta c \leq-\lambda_{1}
\end{array}\right.
$$


Expected profit of the retailer is:

$$
\begin{aligned}
& \pi_{r}=p S(q)+v I(q)-g_{r} L(q)-\left(\Delta c_{r}+c_{r}\right) q-T \\
& =\left(p-v+g_{r}-b\right) S(q)-\left(c_{r}+\Delta c_{r}-v+w_{b}-b\right) q-\mu g_{r}
\end{aligned}
$$

Expected profit of the supply chain is:

$$
\begin{aligned}
& \pi=(p-v+g) S(q)-(c+\Delta c-v) q \\
& -\mu g-\lambda_{1}\left(q-q^{*}\right)^{+}-\lambda_{2}\left(q^{*}-q\right)^{+}
\end{aligned}
$$

The previous buy-back contract cannot coordinate the supply chain after disruptions. We need to reset the parameters $\left(w_{b 1}, b_{1}\right)$ so that retailer's profit is an affine function of the supply chain's, thus $\pi_{r}\left(q, w_{b l}, b_{1}\right)=\lambda+\lambda \mu g-\mu g_{r}$. According to the expression of the retailer's expected profit, we get the corresponding wholesale price and buy-back price:

$$
\left\{\begin{array}{l}
w_{b 3}=w_{b}+(\lambda-1) \Delta c_{r}+\lambda \Delta c_{s}+\frac{\lambda}{q}\left[\lambda_{1}\left(q-q^{*}\right)^{+}+\lambda_{2}\left(q^{*}-q\right)^{+}\right] \\
b_{3}=b
\end{array}\right.
$$

Applying (22) to the profit function of (20) and (21), we can find that the retailer's profit is still an affine function of the supply chain's. The supply chain is coordinated.

\section{NUMERICAL ANALYSIS AND DISCUSSIONS}

Suppose the market demand follows a uniform distribution on the interval $[0,100]$, unit production cost of the supplier $c_{s}=3$, unit marginal cost of the retailer $c_{r}=2$, retail price $p=10$, unit residual value $v=0.5$, unit penalty cost of the supplier $g_{s}=1$, unit penalty cost of the retailer $g_{r}=1$, extra unit $\operatorname{cost} \lambda_{1}=\lambda_{2}=1$, retail price disruption $-2<\Delta p<2$, production cost disruption $-1<\Delta c_{s}<1$, revenue sharing coefficient $\lambda=0.6$. We take retail price disruption and production cost disruption as an example to explore the emergency coordination strategy of buy-back contract.

Fig.1 shows the optimal order quantity in buy-back contract. When disruption stays in a certain range, the quantity remains unchanged; once beyond this range, the optimal order quantity decreases with the increase of production cost and increases with the increase of retail price.

Fig. 2 and Fig. 3 show the wholesale price and buy-back price with the change of disruption. Wholesale price increases with the increase of production cost and retail price. Buy-back price increases with the increase of retail price, but is independent of production cost.

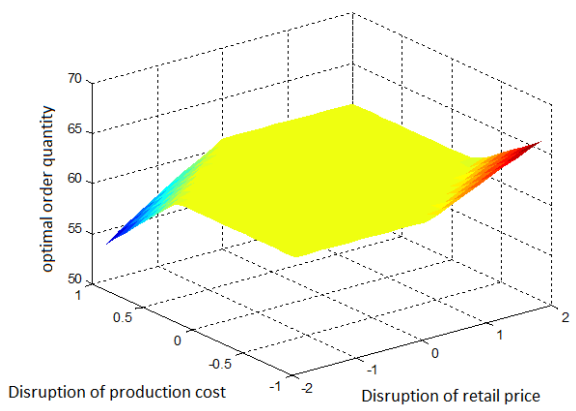

Fig. 1. Optimal order quantity with the change of disruption.

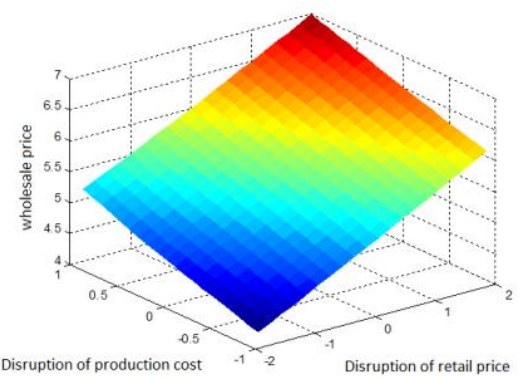

Fig. 2. Wholesale price with the change of disruption.

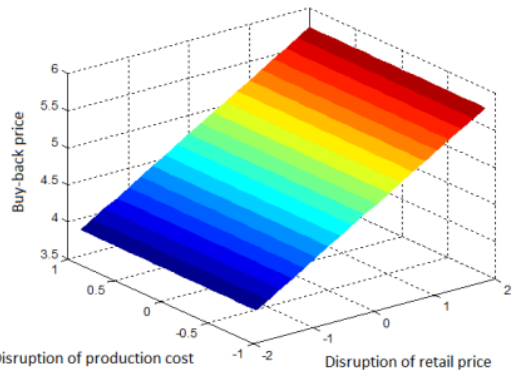

Fig. 3. Buy-back price with the change of disruption

Fig. 4 shows the supplier's profit after adjustment. In the lower left corner of the graph, supplier's profit increases slowly with the decrease of production cost and increase of retail price; in other ranges, supplier's profit increases rapidly.

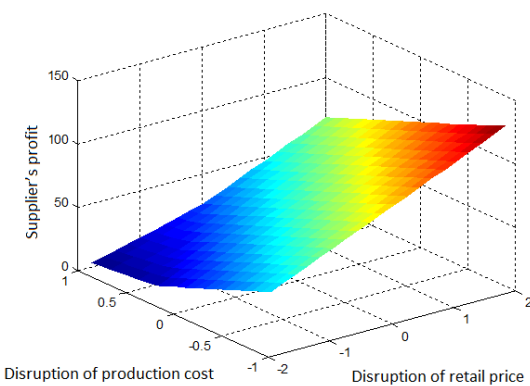

Fig. 4. Supplier's profit with the change of disruption after adjustment.

Fig. 5 shows the retailer's profit after adjustment, which increases evenly with the decrease of production cost and increase of retail price.

Fig. 6 shows the supply chain's profit after adjustment, which increases evenly with the decrease of production cost and increase of retail price. In fact, the profit of the supply chain stays the same before and after adjustment. The change of contract parameters, which only adjusts the allocation of profit inside the supply chain, doesn't affect the overall revenue. 


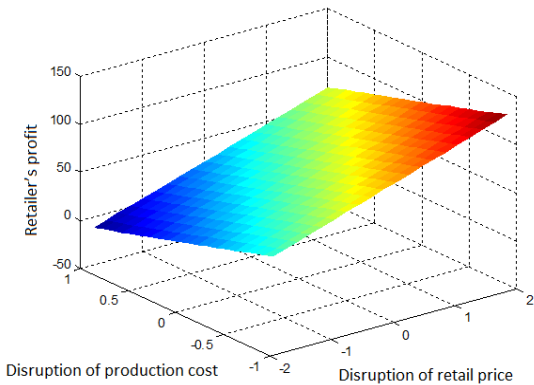

Fig. 5. Supplier's profit with the change of disruption after adjustment.

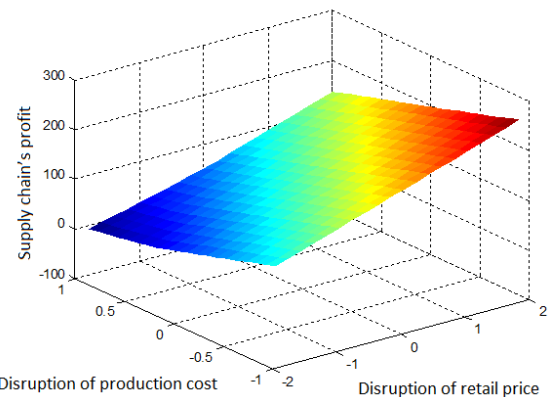

Fig. 6. Supplier's profit with the change of disruption after adjust ment.

\section{CONCLUSIONS}

This paper analyzes the buy-back contract coordination of a dynamic supply chain in which a single supplier sells a single product to a single retailer under the premise of riskneutral. The analysis shows that the original production plan has some robustness when any two factors out of supplier's production cost, retailer's marginal cost and retail price disrupt. When the disruption is small, the optimal order quantity remains unchanged, and we only need to adjust the contract parameters; when the dis ruption is large, we need to adjust the optimal order quantity and contract parameters at the same time. After adjustment, the buy-back contract can coordinate the supply chain.

\section{References}

[1] Yu H, Chen J, Yu G. How to coordinate supply chain under disruptions [J]. Systems Engineering-Theory \& Practice, 2005, 25(7), 9-16 (in Chinese).

[2] Xu M H. The demand disruption management problem for a supply chain system with nonlinear demand functions [J]. Journal of Systems Science and Systems Engineering. 2003. 12(1): 82-97.

[3] Xu M, Yu G and Zhang H. Coordinating dyadic supply chains when production costs are disrupted. IIE Transactions. 2006, 38(9): 765-775.

[4] Zhuang P, Zhao L D. Supply chain wholesale price contract with two competing retailers under asymmetric information and disruption [J]. Journal of Southeast of University (National Science Edition). 2007(11), 37: 413-419 (in Chinese).

[5] Wang H, Hu J S. Coordination mechanism analysis of three-level supply chain under disruption [J]. Journal of Qingdao University, 2006, 9(3) 71-78 (in Chinese).

[6] Qi X, Bard J F, Yu G. Supply chain coordination with demand disruptions [J]. Omega, 2004, 32: 301-312.

[7] Xu M, Qi X, Yu G. The demand disruption management problems for a supply chain system with nonlinear demand functions [J]. Journal of System Science and Systems Engineering, 2003, 12(1): 82-97.

[8] Yu H, Chen J, Yu G. Supply chain coordination under disruptions with buy-back contract [J]. Systems Engineering-Theory \& Practice, 2005, 8(8): $38-43$ (in Chinese).

[9] Niu C Y. The research on disruption management in supply chain on revenue-sharing contract [D]. Department of Management Science and Engineering, Xidian University, Xi-an, 2009 (in Chinese).

[10] Qin Y H, Fu Q. Coordination Strategy for supply chain with buy-back contract [J]. Industrial Engineering Journal, 2010, 2(13): 21-25 (in Chinese). 